\title{
Cytochrome $b_{-245}$ is a flavocytochrome containing FAD and the NADPH-binding site of the microbicidal oxidase of phagocytes
}

\author{
Anthony W. SEGAL, ${ }^{*}$ Iris WEST, ${ }^{*}$ Frans WIENTJES, ${ }^{*}$ Jonathan H. A. NUGENT, $\dagger$ Ashok J. CHAVAN, $\ddagger$ \\ Boyd HALEY, $\ddagger$ Rodolfo C. GARCIA,* Henry ROSEN§ and Geoffrey SCRACE $\|$ \\ Departments of *Medicine and †Biology, University College London, Rayne Institute, University Street, London WCIE 6JJ, U.K., \\ $\ddagger$ College of Pharmacy and Markey Cancer Centre, University of Kentucky, Lexington, KT 40536, U.S.A. \\ $\S$ Department of Medicine, University of Washington, Seattle, WA 98105, U.S.A. \\ and $\|$ The Ludwig Institute for Cancer Research, 91 Riding House Street, London W1P 8BT, U.K.
}

\begin{abstract}
The NADPH oxidase of phagocytic cells is important for the efficient killing and digestion of ingested microbes. A very unusual low-potential cytochrome $b\left(b_{-245}\right)$ is the only redox molecule to have been identified in this system. The FADcontaining flavoprotein that binds NADPH and transfers electrons to the cytochrome has eluded identification for three decades. We show here that the haem/FAD ratio in the membranes does not change significantly on activation of this oxidase, indicating that the FAD is present in the membranes from the outset and not recruited from the cytosol. The FAD content of membranes from cells of patients with X-linked chronic granulomatous disease (CGD) lacking the cytochrome $b$ was roughly one-quarter of that in normal subjects and in autosomal recessive CGD patients lacking the cytosolic protein p47-phox. Similar low amounts of FAD were present in uninduced promyelocytic (HL60) cells, suggesting that the low amount of FAD in cells from X-CGD patients was probably unrelated to this oxidase system. Cytochrome $b_{-245}$ appears to bind both the haem and FAD, in a molar ratio of 2:1. The e.p.r. signal of the purified cytochrome was weak and had an asymmetric $g_{\mathrm{z}}$ peak at $g=3.31$. The purified cytochrome could be partially reflavinated (about $20 \%$ ) in the presence of lipid. Amino acid sequence homology was detected between the $\beta$-subunit of this cytochrome $b$ and the ferredoxin-NADP ${ }^{+}$reductase (FNR) family of reductases in the putative NADPH- and FADbinding sites. ${ }^{32} \mathrm{P}$-labelled 2-azido-NADP was used as a photoaffinity label for the NADPH-binding site. Labelling that was competed off with NADP was observed in the region of the $\beta$-subunit of the cytochrome. No labelling was seen in this region in X-CGD in three subjects in whom this cytochrome was missing and in a third in whom it was present but bore a Pro-His transposition in the putative NADPH-binding site. These studies indicate that cytochrome $b_{-245}$ is a flavocytochrome, the first described in higher eukaryotic cells, bearing the complete electron-transporting apparatus of the NADPH oxidase.
\end{abstract}

\section{INTRODUCTION}

The primary phagocytes of the immune system, neutrophils, monocytes and eosinophils, use an NADPH oxidase system to generate superoxide and other reduced oxygen species when they engulf microbes [reviewed by Segal (1989)]. The importance of this oxidase process is best exemplified by the syndrome of chronic granulomatous disease (CGD) in which its dysfunction predisposes to serious bacterial and fungal infections (Holmes $e t$ al., 1967). Although this oxidase was identified over three decades ago, the molecules involved have proved difficult to identify. An unusual, very-low-potential cytochrome $b$ was discovered and shown to be defective in the more common X-linked form of CGD (Segal \& Jones, 1978; Segal et al., 1983).

In addition to the two subunits of the cytochrome $b$ (Segal, 1987; Parkos et al., 1987), a number of cytosolic proteins are required for activity of this oxidase. p47-phox (Segal et al., 1985; Lomax et al., 1989; Volpp et al., 1989; Rodaway et al., 1990) and p67-phox (Leto et al., 1990; Volpp et al., 1988) were identified through deficiencies causing autosomal recessive CGD. The derived amino acid sequence of these proteins has revealed that they both contain two src homology 3 (SH3; see Pawson, 1988) domains, but gave no further insight into their function. The small GTP-binding protein, p21 rac 1, and an associated GDP dissociation-inhibition factor have been identified as components of the activating mechanism (Abo et al., 1991), at least in the 'cell-free' reconstituted system in vitro (Bromberg \& Pick, 1985). However, the NADPH-binding flavoprotein that transports electrons from the substrate to the cytochrome $b$ has eluded identification.

Apart from the almost universal observation that the nucleotide-binding protein in electron-transport chains is a flavoprotein, there is little doubt that an FAD-containing flavoprotein is an essential component of this NADPH oxidase. FAD enhances (Babior \& Kipnes, 1977), and the analogue 5-deazaFAD inhibits, activity of the solubilized oxidase (Light et al., 1981). Diphenylene iodonium, a potent inhibitor of electron transport which is thought to act at the site of the flavoprotein, is a potent inhibitor of this oxidase (Cross, 1987). Most convincingly, an FAD semiquinone free radical was demonstrated by e.p.r. after the addition of NADPH to membranes from activated, but not from resting, neutrophils (Kakinuma et al., 1986). Analysis of the flavin content of these membranes revealed that it was almost exclusively FAD, and that this FAD was released by denaturation. In addition, little covalently bound flavin was detected. The amounts of FAD in the membranes of neutrophils from patients with CGD lacking cytochrome $b_{-245}$ have been found to be variable, but generally diminished when

Abbreviations used: CGD, chronic granulomatous disease; FNR, ferredoxin-NADP ${ }^{+}$reductase; SH3, src homology 3; p47-phox and p67-phox, $47 \mathrm{kDa}$ and $67 \mathrm{kDa}$ cytosolic protein components of the NADPH oxidase; p21 rac 1, a small GTP-binding protein; PBS, phosphate-buffered saline; TLCK, tosyl-lysylchloromethane; PMA, phorbol myristrate acetate.

I To whom correspondence should be addressed. 
compared with normal cells or those with an autosomal recessive pattern of inheritance (Cross et al., 1982b; Gabig \& Lefker, 1984; Ohno et al., 1986; Bohler et al., 1986), suggesting an association between the haem and FAD, possibly within a flavocytochrome (Cross et al., 1982 b; Bohler et al., 1986). Some partially purified preparations of the solubilized oxidase were found to contain both FAD and haem (Bellavite et al., 1983), which were reduced on addition of NADPH (Cross et al., 1984). Other preparations contained FAD but no haem (Markert et al., 1985; Kakinuma et al., 1987), whereas Doussiere \& Vignais (1985) could detect neither FAD nor haem in their solubilized oxidase.

Neutrophils contain cytochrome $P-450$ reductase (Kojima et $a l ., 1987$ ), which is capable of reducing cytochrome $b_{-245}$ (Isogai et al., 1991), and NADH-cytochrome $b_{5}$ reductase (Badwey et al., 1983), but neither has been shown to have any direc' association with the NADPH oxidase.

Attempts have been made to identify the NADPH-binding protein by affinity labelling with NADPH dialdehyde. This agent produced rather non-specific labelling. Initially the relevant labelled protein was thought to be a $66 \mathrm{kDa}$ membrane protein (Umei et al., 1986), but subsequently it has been suggested that it is cytosolic, with a molecular mass of $66 \mathrm{kDa}$ (Smith et al., 1989) and more recently $32 \mathrm{kDa}$ (Umei et al., 1991).

There have been a variety of studies in which it has been claimed that the reductase has been purified. In all cases it was free of cytochrome $b$. It was found to be associated with FAD (Markert et al., 1985; Kakinuma et al., 1987; Yea et al., 1990; Green \& Pratt, 1990), and Doussiere \& Vignais (1985) found it to be free of all detectable redox molecules. A $45 \mathrm{kDa}$ diphenylene iodonium-binding protein has been purified which appeared to match most closely the properties expected of the reductase of the cytochrome $b$ (Yea et al., 1990).

This study was undertaken to identify the NADPH- and FAD-binding proteins of the NADPH oxidase because of the lack of consensus between preceding investigations.

\section{METHODS}

\section{Purification of cytosol and membranes}

Neutrophils were isolated from $100 \mathrm{ml}$ of blood by Dextran sedimentation, Ficoll/Hypaque density-gradient centrifugation and hypo-osmotic lysis of erythrocytes (Segal \& Jones. 1980).

HL60 cells were cultured as described previously (Roberts et al., 1982). The cells $\left(1 \times 10^{8}-2 \times 10^{8}\right)$ was suspended in $2 \mathrm{ml}$ of phosphate-buffered saline (PBS; $140 \mathrm{~mm}-\mathrm{NaCl}, 9.2 \mathrm{~mm}$ $\mathrm{Na}_{2} \mathrm{HPO}_{4} / 1.3 \mathrm{mM}-\mathrm{NaH}_{2} \mathrm{PO}_{4}, \mathrm{pH} 7.4$ ), divided into $2 \times 1 \mathrm{ml}$ portions and incubated at $37^{\circ} \mathrm{C}$ for $2 \mathrm{~min}$. Phorbol myristate acetate (PMA; $1 \mu \mathrm{g} / \mathrm{ml}$ ) was added to one portion. After $3 \mathrm{~min}, 20 \mathrm{ml}$ of ice-cold PBS was added to each sample and the cells were pelleted at $900 \mathrm{~g}$ at $4{ }^{\circ} \mathrm{C}$ for $5 \mathrm{~min}$. The cells were suspended in $500 \mu \mathrm{l}$ of 'break buffer' [6\% (w/w) sucrose containing Pipes (6 mM, pH 7.3), $\mathrm{KCl}$ (60 mM), $\mathrm{NaCl}$ (1.8 mM), $\mathrm{MgCl}_{2}$ (2.3 mM), di-isopropyl fluorophosphate $(1 \mu \mathrm{M})$, phenylmethanesulphonyl fluoride (1 mM) and tosyl-lysylchloromethane (TLCK; $1 \mu \mathrm{g} / \mathrm{ml}$ )] for $10 \mathrm{~min}$ at $4{ }^{\circ} \mathrm{C}$ and then sonicated for $2 \times 5 \mathrm{~s}$ (MSE $150 \mathrm{~W}$, amplitude 3, low power) and centrifuged at $250000 \mathrm{~g}$ for $30 \mathrm{~min}$ on $0.5 \mathrm{ml}$ gradients of 34 and $15 \%$ (w/w) sucrose in a Sorvail TST55.5 rotor (these solutions contained the same additions as the $6 \%$ sucrose, except that di-isopropyl fluorophosphate was omitted). Membranes at the $15 / 34 \%$ interface were aspirated, diluted with 2 vol. of relaxation buffer [Pipes (10 mM, pH 7.3) with $\left.\mathrm{KOH}, \mathrm{KCl}(100 \mathrm{~mm}), \mathrm{NaCl}(3 \mathrm{~mm}), \mathrm{MgCl}_{2}(3.5 \mathrm{~mm})\right]$ (Borregaard et al., 1983) and pelleted by centrifugation as above.
Measurement of superoxide generation by membranes, and their FAD and cytochrome $b$ content

Pellets were sonicated for $2 \times 1 \mathrm{~s}$ in $500 \mu \mathrm{l}$ of break buffer. Superoxide generation was determined in a dual-beam spectrophotometer in $500 \mu \mathrm{l}$ cuvettes by superoxide dismutase $(50 \mu \mathrm{g} / \mathrm{ml})$ inhibition of cytochrome $c$ reduction $(200 \mu \mathrm{M}$ in $6 \%$ sucrose) (Cross et al., 1984) in the presence of $200 \mu \mathrm{M}-\mathrm{NADPH}$ by the addition of $100 \mu \mathrm{l}$ of membranes to each side.

Cytochrome $b$ was measured in $200 \mu$ l of membranes by dithionite-reduced-minus-oxidized difference spectroscopy. The Soret band was used for quantification because of the small amount of sample. The peak height at $427 \mathrm{~nm}$ over a line drawn between the troughs at 410 and $440 \mathrm{~nm}$ was determined in a purified preparation of the cytochrome as having an absorption coefficient of $121 \pm 10$ (mean \pm S.D., $n=7) \mu \mathrm{M}^{-1} \cdot \mathrm{cm}^{-1}$ by comparison with that at $558 \mathrm{~nm}$ of 21 (Cross et al., 1982a).

FAD was measured by the reconstitution of the activity of apo-(D-amino acid oxidase) (Fossati et al., 1980; Hinkkanen \& Decker, 1983). D-Amino acid oxidase was dialysed overnight at $4{ }^{\circ} \mathrm{C}$ against $\mathrm{KBr}(1 \mathrm{M})$ sodium pyrophosphate (10 mM, pH 8.0). It was then passed down a Hi-load 16/60 Superdex TM75 gelfiltration column (Pharmacia) in the same buffer at $20^{\circ} \mathrm{C}$ at $0.5 \mathrm{ml} / \mathrm{min}$ and then desalted through Sephadex G-10 equilibrated with $\mathrm{Tris} / \mathrm{HCl}(0.1 \mathrm{M}, \mathrm{pH} 8.6)$. The assay mixture contained D-proline (35 mM), 3,5-dichlorobenzenesulphonic acid $(20 \mathrm{mM}), 4$-aminoantipyrene $(0.2 \mathrm{mM})$, D-amino acid oxidase $(0.2 \mathrm{unit} / \mathrm{ml})$ and horseradish peroxidase $(4 \mathrm{units} / \mathrm{ml})$ in the Tris/ $\mathrm{HCl}$ buffer. A portion $(50 \mu \mathrm{l})$ of the membrane suspension was boiled for $3 \mathrm{~min}$, centrifuged at $10000 \mathrm{~g}$ for $2 \mathrm{~min}$ at $4{ }^{\circ} \mathrm{C}$ and FAD concentration determined in 5-30 $\mu$ l of the supernatant.

Protein concentrations were determined by the BCA microassay procedure (Pierce, Rockford, IL, U.S.A.).

\section{Patients}

Six patients with X-linked, and four with autosomal recessive, CGD were studied. Neutrophils from all these subjects demonstrated the complete absence of the PMA-induced respiratory burst. The X-linked-CGD cells were lacking the haem spectrum of the cytochrome $b$, and neither of the cytochrome subunits could be demonstrated by Western immunoblotting. Cells from two of these patients had been used in a previous study (Cross et $a l ., 1982 b$ ) of FAD concentration.

Cells from the autosomal recessive patients were all totally deficient in p47-phox on Western immunoblots of cytosol.

\section{Purification and reflavination of cytochrome $b_{-245}$}

The cytochrome $b$ was purified as described previously (Harper et al., 1984; Segal, 1987). Neutrophil membranes were preextracted with cholate, and the cytochrome was passed through a mixed bed of DEAE, CM- and $\mathrm{N}$-amino-octyl-Sepharoses, chromatographed in heparin-agarose and centrifuged into a sucrose gradient, yielding a specific activity of $11.2 \mathrm{nmol}$ of haem $/ \mathrm{mg}$ of protein. The cytochrome was bound to a small $(2 \mathrm{ml})$ column of heparin-agarose, washed with $20 \mathrm{ml}$ of $40 \mathrm{~mm}$ octyl glucoside in buffer A [Tris/acetate, $\mathrm{pH} 7.4(100 \mathrm{~mm}), \mathrm{KCl}$ $(0.1 \mathrm{M})$, glycerol $(20 \%, \mathrm{v} / \mathrm{v})$, dithiothreitol (1 mM), EDTA (1 mM), phenylmethanesulphonyl fluoride (1 mM) and TLCK $(1 \mu \mathrm{g} / \mathrm{ml})]$ and then eluted in the same buffer containing $0.5 \mathrm{M}-$ $\mathrm{NaCl}$. Phosphatidylethanolamine and phosphatidylcholine (400 $\mu \mathrm{g}$ of each) were dried under a stream of $\mathrm{N}_{2}$, solubilized in $1 \mathrm{ml}$ of the octyl glucoside buffer, mixed with the cytochrome in $2 \mathrm{ml}$ of buffer A and FAD (30 $\mu \mathrm{M})$, and dialysed against buffer A for $48 \mathrm{~h}$ at $4{ }^{\circ} \mathrm{C}$. The precipitated lipid and cytochrome were then layered on a $3 \mathrm{ml}$ cushion of sucrose $(20 \%$, w/w) in sodium phosphate $(10 \mathrm{mM}, \mathrm{pH} 7.4)$ and centrifuged at $300000 \mathrm{~g}$ for $1 \mathrm{~h}$ at $4{ }^{\circ} \mathrm{C}$ in a Kontron TST 41.14 head. The red cytochrome pellet 
was sonicated for $5 \times 1 \mathrm{~s}$ in buffer $\mathrm{A}(2 \mathrm{ml})$ without detergent and then centrifuged through $2.5 \mathrm{ml}$ of the same sucrose at $300000 \mathrm{~g}$ at $4{ }^{\circ} \mathrm{C}$ for $15 \mathrm{~min}$ in a Kontron TST 55.5 head. In control experiments with lipid alone, the dialysed cytochrome and the lipid were pelleted at $300000 \mathrm{~g}$ fo $1 \mathrm{~h}$, and the pellets were resuspended in $4.5 \mathrm{ml}$ of buffer $A$ and repelleted. For recordings of e.p.r. spectra the final pellet was resuspended in buffer $\mathrm{A}$ $(300 \mu \mathrm{l})$ at a concentration of $270 \mu \mathrm{M}$.

\section{E.p.r. spectroscopy}

E.p.r. spectra were recorded with a Jeol RE1X ESR spectrometer fitted with an Oxford Instruments cryostat.

\section{Structural analysis}

The sequence of the $\alpha-$ (C24A\$HUMAN) and $\beta$ (C24B\$HUMAN) subunits of cytochrome $b_{-245}$ were used in searches for homology with proteins in the Swiss Protein database (version 18) and PIR databases. The proposed glycine-rich NADPH-binding domain common to Bacillus megaterium and rat cytochrome $P-450$ reductases and Salmonella typhimurium sulphate reductase (Hurst et al., 1991) GXGXGXXPF, was used to search the Swiss Protein database using the program Scrutineer (Sibbald \& Argos, 1990).

The Swiss database was also searched for common protein motifs with PROSITE (A. Bairoch, University of Geneva, Geneva, Switzerland; release 7.0, 1991) and specifically for nucleotide-binding sites (Bork \& Grunwald, 1990).

Secondary-structure prediction was performed using SEQANAL programs (Professor A. R. Crofts, University of Illinois, Urbana, IL, U.S.A.).

\section{2-Azido-NADP ${ }^{+}$photoaffinity labelling of cytosol and membranes}

2-Azido-NAD ${ }^{+}$was synthesized as described previously (Kim \& Haley, 1990) and labelled with ${ }^{32} \mathrm{P}$ by using $\mathrm{NAD}^{+}$kinase (specific radioactivity between 2 and $20 \mathrm{mCi} / \mu \mathrm{mol}$ ). 2-Azido$\mathrm{NAD}^{+}(208 \mu \mathrm{M})$ was incubated with $\left[\gamma^{-32} \mathrm{P}\right] \mathrm{ATP}(430 \mu \mathrm{M}$, $4.0 \mathrm{mCi}$; ICN Biomedicals) and $\mathrm{NAD}^{+}$kinase (19 units; Sigma) in $0.6 \mathrm{ml}$ of Tris (30 mM, pH 7.5) containing $\mathrm{MgCl}_{2}(5 \mathrm{~mm})$ for $2 \mathrm{~h}$ at $25^{\circ} \mathrm{C}$. The 2-azido-NADP was purified by ion-exchange chromatography on benzyl-DEAE cellulose (Kim \& Haley, 1990). Membranes (100 $\mu \mathrm{g}$ of protein, $1 \mathrm{mg}$ for purification of cytochrome) or cytosol ( $100 \mu \mathrm{g}$ of protein in $10 \mu \mathrm{l}$ of break buffer) were made up to $50 \mu \mathrm{l}$ in Hepes $(20 \mathrm{~mm}, \mathrm{pH} 7.4)$ and $\mathrm{MgCl}_{2}(2 \mathrm{mM})$ in $1.5 \mathrm{ml}$ micro-centrifuge tubes. The probe $(40 \mathrm{Ci} / \mathrm{mmol})$ was dried down from a methanol solution, resuspended in water and added to the incubation mixture in a volume of $10 \mu \mathrm{l}$ at a final concentration of $20 \mu \mathrm{M}$. After $2 \mathrm{~min}$ at $4{ }^{\circ} \mathrm{C}$ the samples were illuminated for $1 \mathrm{~min}$ from a distance of $4 \mathrm{~cm}$ with a $6 \mathrm{~mW} / \mathrm{cm}^{2}$ u.v. lamp (UVP, San Gabriel, CA, U.S.A.; model UVG-54, short-wave u.v. with filter removed). Sample buffer was added and the samples were electrophoresed on $10 \%$ - or $12.5 \%$-acrylamide slab gels. The gels were stained with Coomassie Brilliant Blue, destained and autoradiographed at $-70^{\circ} \mathrm{C}$ with intensifying screens with Hyperfilm MP (Amersham International) after preflashing. In Fig. 5, samples in (a) and $(b)$ were exposed for $18 \mathrm{~h}$ and those in $(c)$ and $(d)$ for 7 days. Low-molecular-mass standards were from Bio-Rad.

All reagents were from Sigma unless otherwise stated.

\section{RESULTS AND DISCUSSION}

\section{FAD and haem in membranes from resting and activated cells}

Our initial aim was to determine the origin of the FAD component of the NADPH oxidase. The active oxidase is present in neutrophil membranes, and FAD was measured in this compartment to establish whether it was present there in resting cells, or recruited in part or in whole from the cytosol on activation.

The activated membranes demonstrated a marked increase in the capacity to generate superoxide, indicating the presence of an active NADPH oxidase system (Table 1). Fig. 1 shows that the concentration of FAD in the membranes of resting cells was very similar to that in activated cells. The slight increase in specific activity of the FAD on activation was mirrored by a similar increase in that of the haem, so that the ratio of FAD/haem remained fairly constant. The slight increase in specific activity of both FAD and haem could result from PMA-induced degranulation of the specific granules (Garcia \& Segal, 1984), resulting in the incorporation of their membranes, possibly with a higher specific activity of redox molecules, into the membrane pool.

The haem spectrum of the cytochrome $b$ is associated with the membranes, and the maintenance of a constant ratio of FAD/ haem on activation indicates that the FAD, like the haem, is present in the membranes from the outset, and that no detectable FAD is recruited from the cytosol. These results support similar experiments with membranes purified from activated porcine cells, indicating a primary location of the flavoprotein in the membranes (Kakinuma et al., 1986), and studies involving the cell-free system in which it was shown that cytosolic components functioned well, although almost free of flavins (Chiba et al., 1990).

The concentrations of FAD in membranes from patients with X-linked CGD were then measured. We (Cross et al., 1982b) and others (Gabig \& Lefker, 1984; Bohler et al., 1986; Ohno et al., 1986) had previously observed a decrease in the FAD content of membranes of neutrophils from these patients to about half of the normal levels. Some of these studies had produced inconsistent results (Ohno et al., 1986; Bohler et al., 1986), possibly because the measurements were made by fluorescence on relatively small amounts of material. Using the more sensitive and specific D-amino acid oxidase assay, we observed markedly decreased concentrations of FAD to less than $30 \%$ of normal in six patients with X-CGD lacking the haem spectrum of cytochrome $b_{-245}$. Normal concentrations of FAD were detected in membranes from the four patients with autosomal recessive CGD whose cells were deficient in the cytosolic factor p47-phox (Fig. 1).

To determine the role of the small amount of FAD in X-CGD membranes, FAD was measured in membranes from uninduced HL60 cells. This is a human promyelocytic cell line that can be induced to differentiate into cells resembling neutrophils. Uninduced cells lack, or are markedly depleted of all known specialized components of the oxidase, which accumulate on differentiation in association with the development of NADPH oxidase activity (Roberts et al., 1982). Concentrations of FAD in undifferentiated HL60 cells, with very low oxidase activity, and the haem spectrum associated with the cytochrome $b$, were similar to those observed in cells from X-CGD patients. This suggests that the low concentrations of FAD found in the membranes of uninduced HL60 and X-CGD cells are probably unrelated to the NADPH oxidase.

Subtracting this presumed unrelated FAD from the total membrane FAD provided a concentration of presumed oxidasespecific FAD which can be related to the haem concentration in the oxidase-specific cytochrome $b$. This comparison yielded a ratio of FAD/haem of roughly $1: 2$ in membranes from unstimulated and stimulated normal neutrophils and those from patients with autosomal recessive CGD. A very similar ratio of FAD/haem was obtained by Bellavite et al. (1983) in peak fractions of a partially purified solubilized oxidase, although in later purifications the ratio fell to 1:19-39 (Bellavite et al., 1984), possibly because of loss of FAD as the purification proceeded. 
Table 1. FAD, haem spectrum of cytochrome $b_{-245}$ and protein concentrations in, and NADPH oxidase activity of, membranes from neutrophils of normal subjects, patients with X-linked CGD (X-CGD) and autosomal recessive CGD (AR-CGD) and uninduced HL60 cells

PMA refers to activation with phorbol myristate acetate, and ND means not detected.

\begin{tabular}{|c|c|c|c|c|c|}
\hline & \multicolumn{2}{|c|}{ Normal } & \multirow{2}{*}{$\begin{array}{c}\text { X-CGD } \\
9\end{array}$} & \multirow{2}{*}{$\begin{array}{c}\text { HL60 } \\
4\end{array}$} & \multirow{2}{*}{$\begin{array}{c}\text { AR-CGD } \\
4\end{array}$} \\
\hline Number... & 12 & 12 & & & \\
\hline $\begin{array}{l}\text { PMA } \\
\text { FAD (pmol/mg of protein) } \\
\text { Haem (pmol } / \mathrm{mg} \text { of protein) } \\
\text { Oxidase }\left(\mathrm{nmol} \mathrm{of} \mathrm{O}_{2}^{-} / \mathrm{mg} \text { of protein) }\right. \\
\text { Protein }(\mathrm{mg} / \mathrm{ml})\end{array}$ & $\begin{array}{c}- \\
436 \pm 190 \\
656 \pm 198 \\
4.5 \pm 2.0 \\
653 \pm 266\end{array}$ & $\begin{array}{l}+ \\
481 \pm 100 \\
770 \pm 111 \\
91.4 \pm 50 \\
616 \pm 172\end{array}$ & $\begin{array}{c}+ \\
128 \pm 37 \\
\mathrm{ND} \\
2.3 \pm 1.8 \\
712 \pm 364\end{array}$ & $\begin{array}{c}- \\
153 \pm 93 \\
133 \pm 44 \\
- \\
575 \pm 296\end{array}$ & $\begin{array}{c}+ \\
383 \pm 92 \\
536 \pm 44 \\
- \\
997 \pm 462\end{array}$ \\
\hline
\end{tabular}

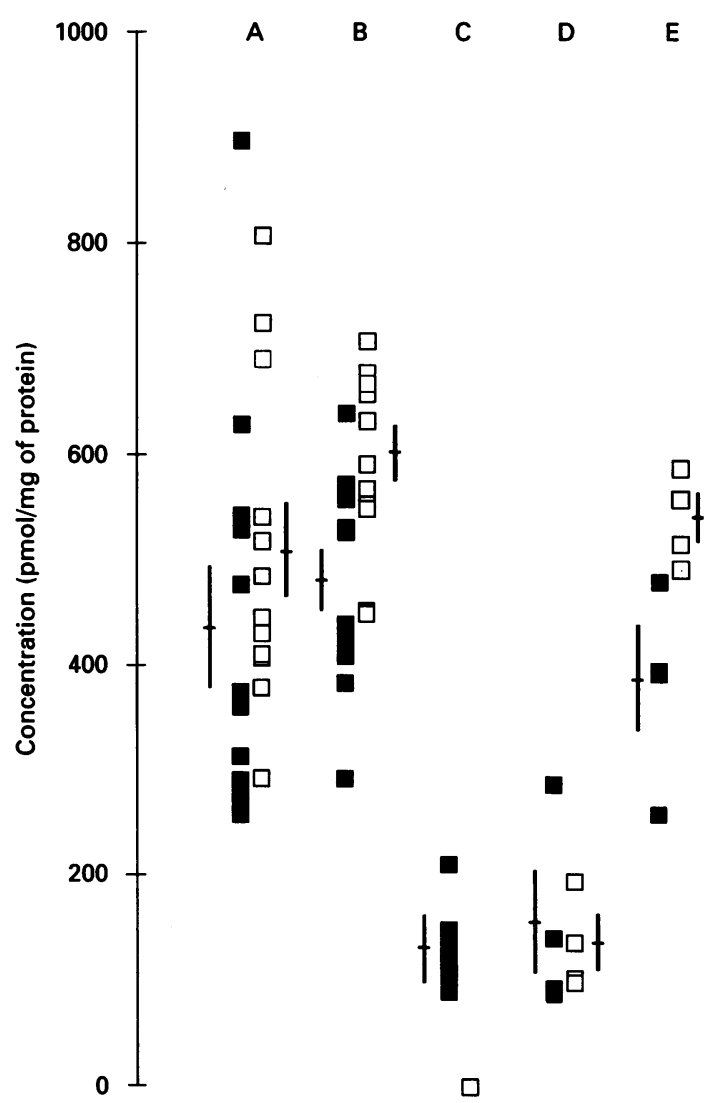

Fig. 1. FAD ( $\square$ ) and haem ( $\square$ ) concentrations (pmol/mg of protein) in membranes from neutrophils of normal subjects before (A) and after (B) activation with PMA, from activated cells from patients with $X$ linked (C) and autosomal recessive (E) CGD, and from uninduced HL60 cells (D)

An FAD/haem ratio of $1: 2$ is important because it provides a mechanism by which the two electrons donated by NADPH and carried by FAD could be separately donated to oxygen to form superoxide, perhaps each being transported by one of the two haems.

\section{E.p.r.}

Previous attempts to identify e.p.r. signals from cytochrome $b_{-245}$ have proved inconclusive, mainly because the signals were obtained from impure cytochrome preparations. Kakinuma et al. (1986) characterized a $g=2.004$ signal in neutrophil membranes as a neutral flavosemiquinone radical and suggested that its relaxation properties indicated a nearby transition-metal centre. They subsequently suggested (Hata Tanaka et al., 1987) that a high-spin haem signal present in partially purified preparations was from this cytochrome $b$. This indicated a possible five-co-ordinate iron with oxygen able to bind as the sixth ligand.

Recent studies have cast doubt on some of these findings. Hurst et al. (1991), in a study using e.p.r. and Raman spectrometry, failed to detect an e.p.r. signal from the partially purified cytochrome. This suggested interactions between, for example, two nearby haems, that might decrease or eliminate the expected signal. Their Raman study of the haem environment indicated a low-spin six-co-ordinate haem with axial imidazole or imadazolate ligands. The stability of the ferric state showed strong donation from the axial ligands which in turn indicated a degree of covalency. It was suggested that the high-spin signal previously described (Hata Tanaka et al., 1987) was due to a damaged protein or to contamination.

Ueno et al. (1991) have investigated the e.p.r. properties of whole neutrophils at $4.2 \mathrm{~K}$, and, setting aside signals due to myeloperoxidase, ascribed signals with $g$ values of $2.85,2.17$ and 1.67 to this cytochrome $b$. On this rather uncertain basis they speculated that this cytochrome is a low-spin six-co-ordinate haem with bis-imidazole ligation, possibly involving both subunits.

In concentrated samples of purified cytochrome $b_{-245}$ we have now detected a low-spin e.p.r. signal as shown in Fig. 2. The lowspin haem has a $g_{z}$ peak at $g=3.31$. Additional signals were seen near $g=2$ and $g=1.5$, but no signals were observed near $g=6$ from high-spin haem. The $g$-value of the $g_{z}$ peak is high for a simple bis-histidine-liganded cytochrome, indicating either a deviation from parallel orientation of axial histidine ligands (Babcock et al., 1985; Safo et al., 1991) or perhaps an axial ligand which is not histidine. Our results are consistent with those of Hurst et al. (1991), as the signal was probably below their level of detection. The $g_{z}$ value is unlike any previously attributed to this cytochrome in impure preparations, suggesting that previous assignments were to impurities or damaged complexes.

Yamaguchi and colleagues appeared to have dissociated and partially separated the $\alpha$ - and $\beta$-subunits and demonstrated the association of the haem with the smaller $\alpha$-subunit (Yamaguchi et al., 1989). However, the amino acid composition they obtained from the purified $\alpha$-subunit was incompatible with that of the amino acid sequence derived from the cDNA (Parkos et al., 1988). Subsequently they have obtained a closer matching composition from a purer sample and have demonstrated that the $22 \mathrm{kDa}$ haem-binding protein cross-reacts with an antiserum to the $\alpha$-subunit of cytochrome $b$ (T. Yamaguchi, personal communication). The radiation-inactivation analysis that we conducted on the haem-binding component pointed to its association with a molecule of slightly more than $20 \mathrm{kDa}$ (Nugent et al., 1989) which could implicate the $\alpha$-subunit itself or the $20-25 \mathrm{kDa}$ hydrophobic domain of the $\beta$-subunit. 


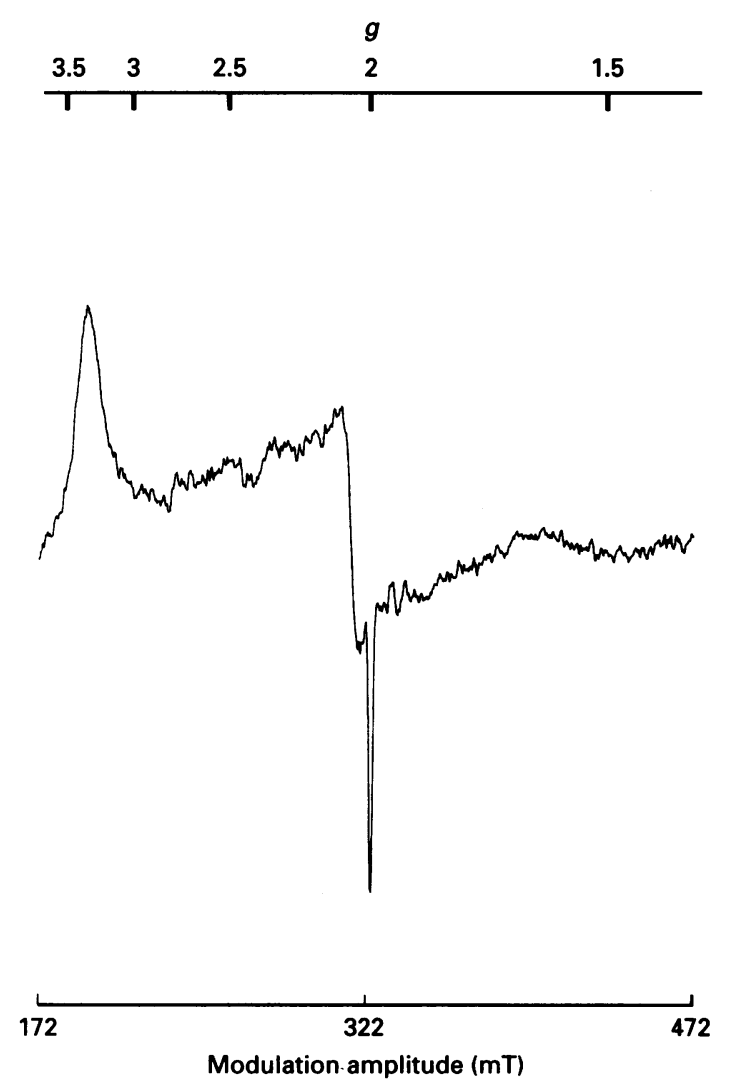

Fig. 2. E.p.r. spectrum of purified cytochrome $b_{-245}$

The oxidized-minus-reduced e.p.r. difference spectrum of the cytochrome is shown. E.p.r. conditions: microwave power $5 \mathrm{~mW}$, modulation amplitude $1.25 \mathrm{mT}$ and temperature $11 \mathrm{~K}$. Cytochrome concentration $270 \mu \mathrm{M}$.

\section{Sequence homology}

The absence of both the haemocytochrome $b$ and FAD in Xlinked CGD suggested that these two redox centres were likely to be located on the same proteins, namely $\alpha$ - and $\beta$-subunits of cytochrome $b_{-245}$, which are absent in this condition. Recent studies have demonstrated strong homologies in flavin- and NADPH-binding domains in the nitrite reductase family of proteins (Karplus et al., 1991 ; Porter, 1991 ; Bredt et al., 1991). We therefore examined the sequences of these proteins for homology with these nucleotide-binding domains.

Initial searches on general homology, and against libraries of common nucleotide-binding sites (Bork \& Grunwald, 1990) and general motifs (PROSITE), were unrewarding. However, a search specifically with the conserved glycine-rich region in the proposed NADPH-binding site of the FNR flavoenzyme family (Porter, 1991) was more productive, showing close homology between the $\beta$-subunit of cytochrome $b_{-245}$ and other members of this family (Fig. 3). All the NADPH-binding proteins exhibited homology with Gly-Xaa-Gly-Xaa-Gly-Xaa-Xaa-Pro-Phe, whereas in the sequence from the two NADH-binding proteins, nitrite and sulphite reductase, the sequence started Gly-Gly and the proline was followed by methionine rather than phenylalanine.

In addition, there was evidence for the presence of the other conserved sequence in the $\mathrm{NAD}(\mathrm{P}) \mathrm{H}$-binding site, Cys-Gly, in the $\beta$-subunit, in which it was located roughly 130 amino acids to the $C$-terminus of the first glycine rather than the approx. 100 amino acids found in the FNR family.

Homology was also detected in the region of the FADisoalloxazine-binding site approx. 90 amino acids upstream of the NADPH-ribose-binding site. Although direct homology was

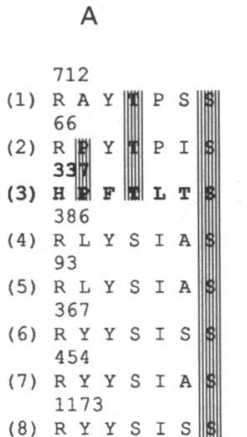
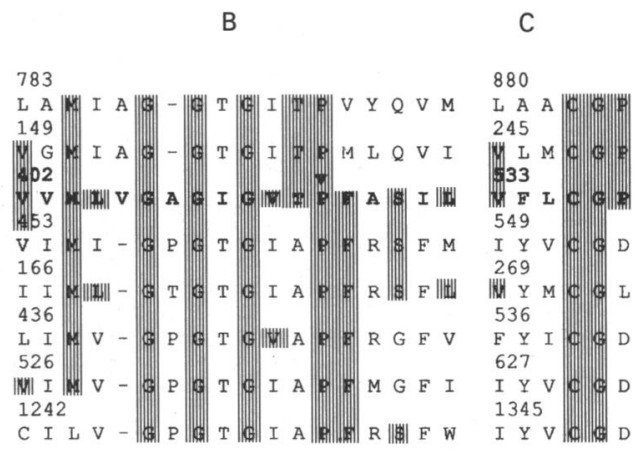

$\begin{array}{ll}\text { Enzyme } & \text { Source } \\ \text { (1) NADH-nitrate reductase } & \text { Tomato } \\ \text { (2) NADH-cytochrome } b 5 \text { reductase } & \text { Human } \\ \text { (3) NADPH-cytochrome } \boldsymbol{b} \text {-245, } \boldsymbol{\beta} \text {-chain } & \text { Human } \\ \text { (4) NADPH-sulphite reductase } & \text { Salmonella typhimurium } \\ \text { (5) Ferredoxin-NADP }{ }^{+} \text {reductase } & \text { Spinach } \\ \text { (6) NADPH-cytochrome P-450 reductase } & \text { Bactillus megaterium } \\ \text { (7) NADPH-cytochrome P-450 reductase } & \text { Rat } \\ \text { (8) NADPH-nitric oxide synthase } & \text { Rat }\end{array}$

Fig. 3. Sequence alignment of reductases and the $\beta$-subunit of cytochrome $b_{-245}$ in the proposed conserved FAD- (A) and NAD(P)H- (B and C) binding sites

Sequences are from the Swiss Database, except (8) (Bredt et al., 1991). The site of the Pro-His mutation in the patient with X-CGD (Hurst et al., 1991) is indicated ( $\nabla)$.

weak, the amino acids in this region corresponded closely to those in the FNR family in charge, size and function. The highly conserved tyrosine residues in this region and in the Cys-Gly dipeptide NADPH-binding segment of the FNR family have both been replaced by phenylalanine in the cytochrome $b$. The structural differences in the FAD-binding domain might explain the relative instability of FAD binding in the cytochrome $b$ as compared with other members of this family.

Apart from these specific binding sites, a general comparison between the alignment of the distal 250 amino acids in the hydrophilic region of the cytochrome $b$ with the FNR family of reductases indicated overall homology, the alignment score was greater than ten S.D.s above the mean value obtained for alignments when the sequence of the cytochrome was randomized. (P. A. Karplas, personal communication).

A single patient with CGD (Dinauer et al., 1989) has been described in whom the pattern of inheritance was clearly Xlinked, and yet the cytochrome $b$ was clearly present, demonstrating normal light and Raman spectra and mid-point potential, indicating little if any abnormality of the haem environment of the cytochrome (Hurst et al., 1991). FAD concentrations in the membranes were normal $(320 \mathrm{pmol} / \mathrm{mg})$. A point mutation has been identified in his $\beta$-chain gene resulting in the substitution of histidine for proline at amino acid 414 (415, including $N$-terminal methionine) (Dinauer et al., 1989). It is significant that this substitution is located in the glycine-rich region of the predicted NADPH-binding pocket, a change that would be expected to impair its affinity for this nucleotide severely.

One X-linked patient has been identified whose membranes contained normal amounts of haem but were deficient in FAD [patient MK in Gabig \& Lefker (1984)]. It seems probable that his mutation would involve the FAD-binding site. 
(a)
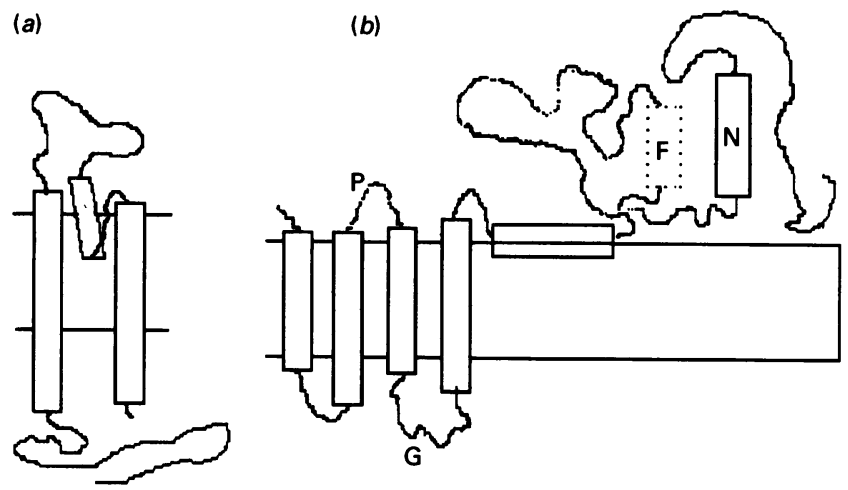

Fig. 4. Schematic representation showing the main predicted structural features of cytochrome $b_{-245} \alpha$ - and $\beta$-subunits

(a) $\alpha$-subunit showing predicted membrane spans. No information is available on the orientation in the membrane but our prediction suggests that the $C$-terminus is located towards the exterior. (b) $\beta$ subunit showing membrane spans. The $C$-terminal hydrophilic region is known to be located in the cytosol (Rotrosen et al., 1990). This locates the consensus NADPH- binding site (N) and the possible FAD-binding site (F) on the cytosolic side of the membrane. The possible glycosylation site $(\mathrm{G})$ motif $\mathrm{N}-\mathrm{X}-(\mathrm{T} / \mathrm{S})$ has been located towards the outside of the membrane and possible phosphorylation motif R-X-S-S towards the cytosol (P). Both these sites are located on predicted turns at the membrane surface.

Secondary-structure prediction using the amino acid sequences of both the $\alpha$ - (Parkos et al., 1988) and $\beta$ - (Royer-Pokora et al., 1986; Teahan et al., 1987) subunits indicate that both subunits have transmembrane helical spans. There are up to six helical hydrophobic regions in the $\beta$-subunit, suggesting up to six possible membrane spans, and probably two membrane-spanning helices in the $\alpha$-subunit. A schematic representation of the general structural features of the two subunits is shown in Fig. 4. The initial 240 amino acids of the 569 in the $\beta$-subunit form a hydrophobic domain. Included within this are several histidines that could bind haems and a pair of histidines at residues 208 and 209 which are identified by PROSITE as a potential copperbinding site. By analogy with cytochrome oxidase, cysteines, which would be required to bind to the copper, are present in an appropriate position on the transmembrane spans at residues 58 , 63 and 184. From approximately residue 240 the character of the protein then changes to a predominantly hydrophilic sequence containing the NADPH consensus binding site and possibly the site of FAD binding.

\section{NADPH affinity labelling of membranes and cytosol}

Having identified the probable NADPH-binding site, we attempted to strengthen this evidence by demonstrating direct binding of the nucleotide to the $\beta$-subunit of the cytochrome. Dialdehydes of NADH and NADPH have been used as inhibitors of, and affinity ligands to, the binding sites of dehydrogenases (Coleman, 1983). A number of attempts have been made to identify the nicotinamide nucleotide-binding site by the use of NADPH dialdehyde followed by reduction with $\mathrm{NaB}^{3} \mathrm{H}_{4}$. Many proteins in membranes and cytosol have been labelled by this method. Minakami and co-workers thought that the major binding protein in membranes, which they took to represent the oxidase nucleotide-binding site, had a molecular mass of $66 \mathrm{kDa}$ on SDS/PAGE (Umei et al., 1986). Babior, Curnutte and colleagues believe the NADPH-binding site to be in a cytosolic protein that translocates to the membrane, and initially identified a $66 \mathrm{kDa}$ protein (Smith et al., 1989), and more recently one at $32 \mathrm{kDa}$ (Umei et al., 1991). (a)

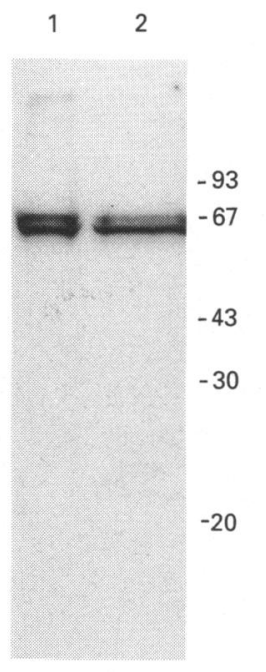

(d)

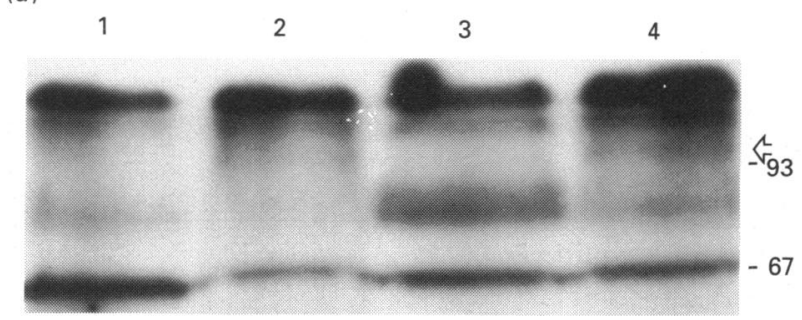

Fig. 5. 2-Azido-NADP photoafinity labelling of (a) cytosol, (b) membranes, (c) semi-pure cytochrome $b_{-245}$ and (d) membranes from normal subjects and patients with X-CGD

In $(a)$ and $(b)$, labelling was in the absence (lane 1) or presence (lane 2) of 1 mM-unlabelled NADP ${ }^{+}$. In $(c)$, the intact membranes from unstimulated (lane 1) and PMA-stimulated (lanes 2-4) cells were separated, labelled in the absence (lanes 1 and 2) or presence of unlabelled NADP ${ }^{+}(100 \mu \mathrm{M}$ in lane 3 and $500 \mu \mathrm{M}$ in lane 4), and the cytochrome $b$ was partially purified as described previously (Segal, 1987). (d) Labelling of the $\beta$-subunit of cytochrome $b_{-245}$ in membranes from two normal subjects (lanes 2 and 4), which is not labelled in a patient with classical X-linked CGD missing the cytochrome $b$ (lane 1 ) or the patient with an X-linked inheritance whose cells contained the $\beta$-subunit, in which there has been a proline to histidine mutation in the putative NADPH-binding site (lane 3, see Fig. 3). SDS/PAGE was in $10 \%$ acrylamide in $(a)$ and $(c)$ and $12.5 \%$ acrylamide in $(b)$ and $(d)$. The arrows identify the location of the $\beta$-subunit of cytochrome $b_{-245}$. It is heavily glycocsylated (Harper et al., 1985) and runs as a broad ill-defined band just above the upper molecular-mass marker. The location of molecularmass markers (in $\mathbf{k D a}$ ) is shown.

In view of the previous uncertainties about NADPH dialdehyde, we decided to use the photoaffinity ligand 2-azidoNADP $^{+}$(Kim \& Haley, 1990; A. J. Chavan \& B. E. Haley, unpublished work). In cytosol this agent almost exclusively labelled two bands with molecular masses of about $67 \mathrm{kDa}$ (Fig. $5 a$ ). The probe was partially displaced from the upper band by unlabelled nucleotide at a concentration of $200 \mu \mathrm{M}$, whereas labelling of the lower band was enhanced.

In membranes (Fig. $5 b$ ), the strongest bands were in the region of the $43 \mathrm{kDa}$ and $67 \mathrm{kDa}$ markers, and at about $35 \mathrm{kDa}$. Weaker bands were observed in the region of the large subunit of the cytochrome at the $93 \mathrm{kDa}$ marker, and at about $32 \mathrm{kDa}$. However, labelling in the $93 \mathrm{kDa}$ and $32 \mathrm{kDa}$ regions was almost completely inhibited by $1 \mu \mathrm{M}$ unlabelled $\mathrm{NADP}^{+}$, indicative of specific labelling, whereas that at $43 \mathrm{kDa}$ was partially decreased, and that at about $67 \mathrm{kDa}$ was unaffected. Although 
identification and signal intensity were hampered by the diffuse band of migration observed with this heavily glycosylated protein (Harper et al., 1985), the $\beta$-subunit was found to be labelled after the cytochrome had been labelled in situ in the membranes, and then partially purified (Fig. 5c). This labelling was not influenced by the state of activation of the membranes, but was almost completely obliterated by $100 \mu \mathrm{M}$ unlabelled NADP. We then attempted to label the membranes from patients with X-CGD lacking this cytochrome $b$. Because of the relatively small amount of material, the proteins were electrophoresed into higherpercentage acrylamide in order to concentrate the highmolecular-mass bands and improve their visual detection. No labelling in the region of the large subunit of the cytochrome was detected in membranes from all three such individuals (one example is shown in Fig. 5d).

We then examined the labelling of this molecule in the X-CGD patient in whom this protein is present, but bearing a point mutation in the putative NADPH-binding site which would be predicted to disrupt severely the topology of this region and prevent the binding of NADPH. A radiolabelled band of the appropriate molecular mass was clearly missing from his membranes (Fig. $5 d$ ).

\section{Reflavination of cytochrome $b$}

Solubilization of membranes with Triton X-100 and N101, octyl glucoside or dodecyl maltoside released most of the membrane cytochrome $b$ and FAD. However, the FAD was not associated with protein, being almost entirely included in Sephadex G-10 desalting columns. Attempts to stabilize the protein-bound FAD by cross-linking with 1-ethyl-3-(3dimethylaminopropyl)carbodi-imide, which has been shown to stabilize the solubilized oxidase (Tamura et al., 1989), were unsuccessful. Pick and co-workers had shown that the cytochrome $b$, which was free of FAD, could alone replace whole membranes in the cell-free system, but only if it was relipidated before use (Knoller et al., 1991). We therefore attempted to reflavinate this molecule after purification, by incubation with FAD and detergent-solubilized lipid followed by removal of the detergent by dialysis. The cytochrome $b$ was then separated from free FAD on sucrose gradients.

We were able to obtain the association of FAD with the cytochrome in a flavin/haem ratio of $0.10 \pm 0.08: 1 \quad(n=8)$, indicating reflavination of $20 \%$ of the cytochrome in the case of a ratio of $0.5: 1$ in membranes. The FAD did not associate with the cytochrome in the absence of lipid, or with lipid in the absence of the cytochrome.

\section{Conclusion}

Although none of the approaches described above independently provides conclusive proof, together they provide strong evidence that the NADPH-binding flavoprotein of the NADPH oxidase is cytochrome $b_{-245}$. Further evidence against the involvement of any other specialized redox proteins comes from the analysis of patients with CGD. All of the approximately 150 patients with CGD described in two large studies (Clark et al., 1989; Casimir et al., 1992) could be classified in terms of a lesion of the two components of cytochrome $b_{-245}$. In addition, Pick and co-workers have shown that in the cell-free system the only required membrane component is the cytochrome $b$ (Knoller et al., 1991). This would identify this molecule as the first flavocytochrome to have been described in higher eukaryotic cells, adding to its unusual features of a very low mid-point potential and the ability to bind $\mathrm{CO}$, in common with microbial cytochromes $o$ (Poole, 1983).

The $\beta$-subunit of this flavocytochrome appears to be distantly related to the FNR family of reductases which are constructed on a modular basis (Porter, 1991), with the different modules representing binding sites for FMN, FAD and NADPH. In the case of this flavocytochrome $b$ an additional module containing the haems has been added, on the $\alpha$-subunit, on the hydrophobic $N$-terminal region of the $\beta$-subunit or between the two.

It is of considerable interest that weak homology at about $20 \%$ extending over the whole molecule has been identified between yeast ferrireductase, an NADPH-binding FAD-containing flavoprotein, and the $\beta$-subunit of this flavocytochrome (A. Dancis, personal communication). A close comparison of these two molecules should greatly assist structural analysis of flavocytochrome $b$, in particular with regard to the haem-binding regions of the molecule.

Having located the complete electron-transport chain within this flavocytochrome $b$, it will be of considerable interest to define the role of the two specialized cytosolic components of the system, p47-phox and p67-phox. It could be that, together with kinases and other regulatory proteins such as p21 rac 1 (Abo et al., 1991), they govern conformational changes in the cytochrome that facilitate electron transport. These observations provide explanations for the difficulties that have been experienced over the years in identifying the proximal redox molecule in this electron-transport chain (Rossi, 1986; Cross \& Jones, 1991). The essence of the problem has been that the physiologically activated oxidase is an efficient electron-transport chain requiring the integrated function of the flavocytochrome $b$ and the two specialized cytosolic factors, as well as the as yet undefined activating mechanisms. Both reductase and oxidase activity are undetectable before activation, after which electron transport is coupled and diaphorase activity absent (Rossi, 1986). The oxidase is very unstable after solubilization of the membranes with detergents, particularly in the presence of salts. The reason for this instability is unclear, one possibility being dissociation of the different components of the oxidase. In the light of this study, it seems likely that at least one cause of this instability is dissociation of the FAD on solubilization.

We thank the Wellcome Trust and Medical Research Council for support, Stuart Harbron, Emma Plummer and Mark Fisher for assistance with the FAD assay, and Sandro Ghisla and Vincent Massey for helpful discussions. H. R. received support from Grant A125606 from the National Institutes of Health

\section{REFERENCES}

Abo, A., Pick, E., Hall, A., Totty, N., Teahan, C. G. \& Segal, A. W. (1991) Nature (London) 353, 668-670

Babcock, G. T., Widger, W. R., Cramer, W. A., Oertling, W. A. \& Metz, J. G. (1985) Biochemistry 24, 3638-3645

Babior, B. M. \& Kipnes, R. S. (1977) Blood 50, 517-524

Badwey, J. A., Tauber, A. I. \& Karnovsky, M. L. (1983) Blood 62 , 152-157

Bellavite, P., Cross, A. R., Serra, M. C., Davoli, A., Jones, O. T. \& Rossi, F. (1983) Biochim. Biophys. Acta 746, 40-47

Bellavite, P., Jones, O. T. G., Cross, A. R., Papini, E. \& Rossi, F. (1984) Biochem. J. 223, 639-648

Bohler, M. C., Seger, R. A., Mouy, R., Vilmer, E., Fischer, A. \& Griscelli, C. (1986) J. Clin. Immunol. 6, 136-145

Bork, P. \& Grunwald, C. (1990) Eur. J. Biochem. 191, 347-358

Borregaard, N., Heiple, J. E., Simons, E. R. \& Clark, R. E. (1983) J. Cell Biol. 97, 52-61

Bredt, D. S., Hwang, P. M., Glatt, C. E., Lowenstein, C., Reed, R. R. \& Snyder, S. H. (1991) Nature (London) 351, 714-718

Bromberg, Y. \& Pick, E. (1985) J. Biol. Chem. 260, 13539-13545

Casimir, C. M., Chetty, M., Bohler, M. C., Garcia, R., Fischer, A., Griscelli, C., Johnson, B. \& Segal, A. W. (1992) Eur. J. Clin. Invest., in the press

Chiba, T., Kaneda, M., Fujii, H., Clark, R. A., Nauseef, W. M. \& Kakinuma, K. (1990) Biochem. Biophys. Res. Commun. 173, 376-381 
Clark, R. A., Malech, H. L., Gallin, J. I., Nunoi, H., Volpp, B. D., Pearson, D. W., Nauseef, W. M. \& Curnutte, J. T. (1989) N. Engl. J. Med. 321, 647-652

Coleman, R. F. (1983) Annu. Rev. Biochem. 52, 67-91

Cross, A. R. (1987) Biochem. Pharmacol. 36, 489-493

Cross, A. R. \& Jones, O. T. G. (1991) Biochim. Biophys. Acta 1057, 281-298

Cross, A. R., Higson, F. K., Jones, O. T. G., Harper, A. M. \& Segal, A. W. (1982a) Biochem. J. 204, 479-485

Cross, A. R., Jones, O. T. G., Garcia, R. \& Segal, A. W. (1982b) Biochem. J. 208, 759-763

Cross, A. R., Parkinson, J. F. \& Jones, O. T. G. (1984) Biochem. J. 223, 337-344

Dinauer, M. C., Curnutte, J. T., Rosen, H. \& Orkin, S. H. (1989) J. Clin. Invest. 84, 2012-2016

Doussiere, J. \& Vignais, P. V. (1985) Biochemistry 24, 7231-7239

Fossati, P., Prencipe, L. \& Berti, G. (1980) Clin. Chem. 26, 227-231

Gabig, T. G. \& Lefker, B. A. (1984) J. Clin. Invest. 73, 701-705

Garcia, R. C. \& Segal, A. W. (1984) Biochem. J. 219, 233-242

Green, T. R. \& Pratt, K. T. (1990) J. Biol. Chem. 265, 19324-19329

Harper, A. M., Dunne, M. J. \& Segal, A. W. (1984) Biochem. J. 219, 519-527

Harper, A. M., Chaplin, M. F. \& Segal, A. W. (1985) Biochem. J. 227, 783-788

Hata Tanaka, A., Chiba, T. \& Kakinuma, K. (1987) FEBS Lett. 214 279-284

Hinkkanen, A. \& Decker, K. (1983) Anal. Biochem. 132, 202-208

Holmes, B., Page, A. R. \& Good, R. A. (1967) J. Clin. Invest. 46, 1422-1432

Hurst, J. K., Loehr, T. M., Curnutte, J. T. \& Rosen, H. (1991) J. Biol. Chem. 266, 1627-1634

Isogai, Y., Shiro, Y., Nasuda-Kouyama, A. \& Iizuka, T. (1991) J. Biol. Chem. 266, 13481-13484

Kakinuma, K., Kaneda, M., Chiba, T. \& Ohnishi, T. (1986) J. Biol. Chem. 261, 9426-9432

Kakinuma, K., Fukuhara, Y. \& Kaneda, M. (1987) J. Biol. Chem. 262, 12316-12322

Karplus, P. A., Daniels, M. J. \& Herriott, J. R. (1991) Science 251, 60-66

Kim, H. \& Haley, B. E. (1990) J. Biol. Chem. 265, 3636-3641

Knoller, S., Shpungin, S. \& Pick, E. (1991) J. Biol. Chem. 266, 27952804

Kojima, H., Takahashi, K., Sakane, F. \& Koyama, J. (1987) J. Biochem. (Tokyo) 102, 1083-1088

Leto, T. L., Lomax, K. J., Volpp, B. D., Nunoi, H., Sechler, J. M. G., Nauseef, W. M., Clark, R. A., Gallin, J. I. \& Malech, H. L. (1990) Science 248, 727-730

Light, D. R., Walsh, C., O'Callaghan, A. M., Goetzl, E. J. \& Tauber, A. I. (1981) Biochemistry 20, 1468-1476

Lomax, K. J., Leto, T. L., Nunoi, H., Gallin, J. I. \& Malech, H. L. (1989) Science 245, 409-412

Markert, M., Glass, G. A. \& Babior, B. M. (1985) Proc. Natl. Acad. Sci. U.S.A. 82, 3144-3148
Nugent, J. H. A., Gratzer, W. \& Segal, A. W. (1989) Biochem. J. 264, 921-924

Ohno, Y., Buescher, E. S., Roberts, R., Metcalf, J. A. \& Gallin, J. I. (1986) Blood 67, 1132-1138

Parkos, C. A., Allen, R. A., Cochrane, C. G. \& Jesaitis, A. J. (1987) J. Clin. Invest. 80, 732-742

Parkos, C. A., Dinauer, M. C., Walker, L. E., Allen, R. A., Jesaitis, A. J. \& Orkin, S. H. (1988) Proc. Natl. Acad. Sci. U.S.A. 85, 3319-3323 Pawson, T. (1988) Oncogene 3, 491-495

Poole, R. K. (1983) Biochim. Biophys. Acta 726, 205-243

Porter, T. D. (1991) Trends Biochem. Sci. 16, 154-158

Roberts, P. J., Cross, A. R., Jones, O. T. \& Segal, A. W. (1982) J. Cell. Biol. 95, 720-726

Rodaway, A. R. F., Teahan, C. G., Casimir, C. M., Segal, A. W. \& Bentley, D. L. (1990) Mol. Cell. Biol. 10, 5388-5396

Rossi, F. (1986) Biochim. Biophys. Acta 853, 65-89

Rotrosen, D., Kleinberg, M. E., Nunoi, H., Leto, T. L., Gallin, J. I. \& Malech, H. L. (1990) J. Biol. Chem. 265, 8745-8750

Royer-Pokora, B., Kunkel, L. M., Monaco, A. P., Goff, S. C., Newburger, P. E., Baehner, R. L., Cole, F. S., Curnutte, J. T. \& Orkin, S. H. (1986) Nature (London) 322, 32-38

Safo, M. K., Gupta, G. P., Walker, F. A. \& Scheidt, W. R. (1991) J. Am. Chem. Soc. 113, 5497-5510

Segal, A. W. (1987) Nature (London) 326, 88-91

Segal, A. W. (1989) J. Clin. Invest. 83, 1785-1793

Segal, A. W. \& Jones, O. T. G. (1978) Nature (London) 276, 515-517

Segal, A. W. \& Jones, O. T. G. (1980) FEBS Lett. 110, 111-114

Segal, A. W., Cross, A. R., Garcia, R. C., Borregaard, N., Valerius, N. H., Soothill, J. F. \& Jones, O. T. (1983) N. Engl. J. Med. 308, 245-251

Segal, A. W., Heyworth, P. G., Cockcroft, S. \& Barrowman, M. M. (1985) Nature (London) 316, 547-549

Sibbald, P. R. \& Argos, P. (1990) Comput. Appl. Biosci. 6, 279-288

Smith, R. M., Curnutte, J. T. \& Babior, B. M. (1989) J. Biol. Chem. 264 1958-1962

Tamura, M., Tamura, T., Burnham, D. N., Uhlinger, D. J. \& Lambeth, J. D. (1989) Arch. Biochem. Biophys. 275, 23-32

Teahan, C., Rowe, P., Parker, P., Totty, N. \& Segal, A. W. (1987) Nature (London) 327, 720-721

Ueno, I., Fujii, S., Ohya-Nishiguchi, H., Iizuka, T. \& Kanegasaki, S. (1991) FEBS Lett. 281, 130-132

Umei, T., Takeshige, K. \& Minakami, S. (1986) J. Biol. Chem. 261, 5229-5232

Umei, T., Babior, B. M., Curnutte, J. T. \& Smith, R. M. (1991) J. Biol. Chem. 266, 6019-6022

Volpp, B. D., Nauseef, W. M. \& Clark, R. A. (1988) Science 242, 1295-1297

Volpp, B. D., Nauseef, W. M., Donelson, J. E., Moser, D. R. \& Clark, R. A. (1989) Proc. Natl. Acad. Sci. U.S.A. 86, 7195-7199

Yamaguchi, T., Hayakawa, T., Kaneda, M., Kakinuma, K. \& Yoshikawa, A. (1989) J. Biol. Chem. 264, 112-118

Yea, C. M., Cross, A. R. \& Jones, O. T. G. (1990) B̈iuchism. J. 265, 95-100

Received 17 September 1991/19 November 1991; accepted 2 December 1991 